\title{
A New Lateral Neck Mass in a 63-year-old Man with Multi-nodular Goiter
}

Nguyen Nguyen ${ }^{1}$, Daniel Neelon ${ }^{1}$, Michael Orestes ${ }^{1}$, Mohamed Shakir ${ }^{1}$, and Thanh Hoang ${ }^{1}$ ${ }^{1}$ Walter Reed National Military Medical Center

January 7, 2021

\begin{abstract}
Described is an atypical presentation of a rare condition. It highlights the importance of thorough algorithm of medical and family history, physical examination, appropriate investigations and perioperative workup and for surgery. This case raises the awareness that a lateral neck mass (or lateral ectopic thyroid mass) can be benign.
\end{abstract}

\section{Hosted file}

Ectopic thyroid tissue in a lateral neck mass.pdf available at https://authorea.com/users/ 388006/articles/502867-a-new-lateral-neck-mass-in-a-63-year-old-man-with-multi-nodulargoiter

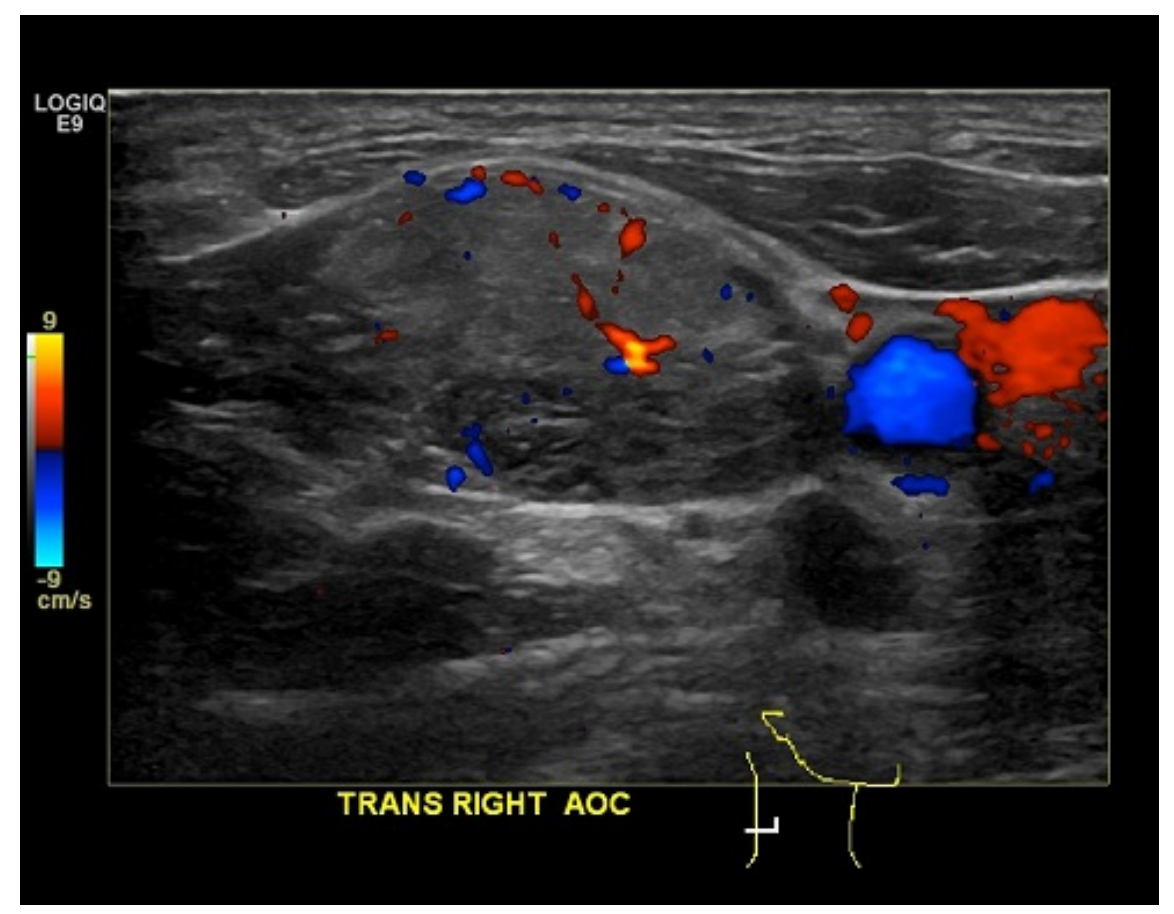



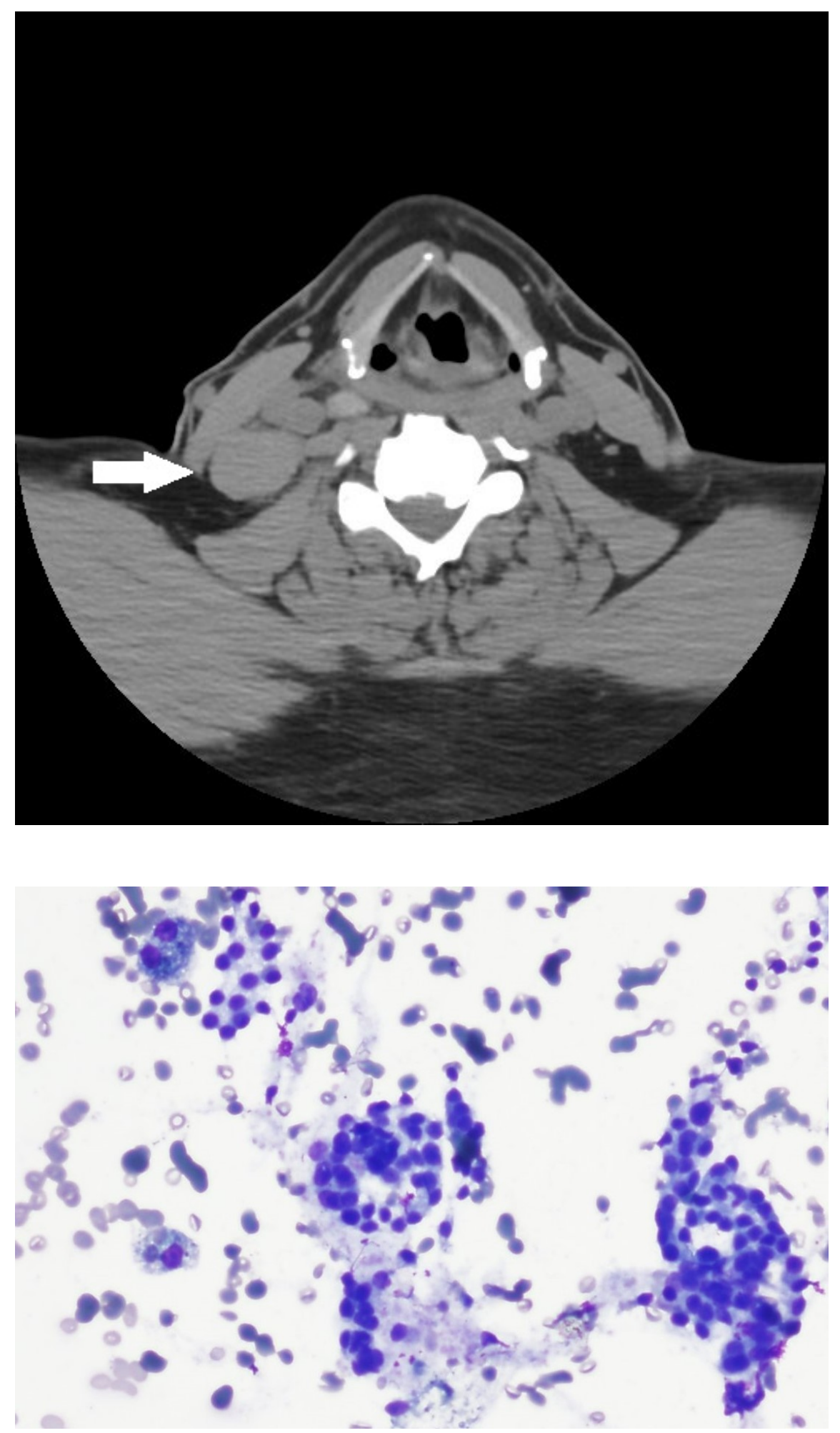